\title{
Cerebellar astrocytomas in children and young adults
}

\author{
CHARLES H DAVIS, * VIJAY M JOGLEKAR† \\ From the Neurosurgical Unit of Guy's, Maudsley and King's College Hospitals, ${ }^{*}$ and the \\ Department of Neuropathology, Institute of Psychiatry, $\dagger$ London
}

SUMMARY A clinical and pathological review of 43 cases of cerebellar astrocytomas in children and young adults was undertaken. Thirty-one of the 36 surviving patients were examined by computed tomography. Twelve patients with asymptomatic tumour were detected. Histology was necessary to identify the higher risk "diffuse" group, but no histological features helped to identify tumours liable to recur. Improvements in the prognosis may occur with long term CT scanning.

Since Cushing in $1931^{1}$ described successful surgery for cerebellar astrocytomas, studies based on well documented prolonged follow-up show that these tumours carry a favourable prognosis ${ }^{2-9}$ following surgery. However, these studies also show that a proportion of patients have a poorer prognosis through tumour recurrence. ${ }^{10}$ The present study aims to investigate further the reasons for this and the behaviour of these tumours following surgery with the contribution of computed tomography (CT) in the assessment after operation. Implications for the management of these patients are discussed.

\section{Material}

From 1951 to 1978,52 patients with a diagnosis of cerebellar astrocytoma were admitted to the Neurosurgical Unit of Guy's, Maudsley and King's College Hospitals. Five patients could not be traced, two patients were brain dead on admission and a further two patients had had initial surgery elsewhere; these nine cases were excluded from this review. The remaining 43 cases formed the pathological basis of this review. Seven of the 43 cases had died. Histological material could be traced for 41 cases. For two further cases only the original pathological report was available. Thirty-six surviving patients were submitted to physical examination, 31 of these with a CT scan (after informed discussion). Five patients refused CT. Of the 43 original patients, 20 cases were male and 23 were female; 35 patients were under 15 years of age and eight were between 15 and 30 years at the time of initial surgery (table 1).

Address for reprint requests: $\mathrm{Mr} \mathrm{CH}$ Davis, Department of Neurological Surgery, The National Hospital, Queen Square, London WC1E 3BG, UK.

Accepted 1 July 1981

\section{Method}

In every case at initial surgery, immediate examination of the operative specimen was performed on toluidine blue stained smears. Fixed specimens were subsequently cut and stained with haematoxylin and eosin; special neuropathological staining techniques were used in some cases. During the physical and neurological examination for this study, particular attention was paid to cerebellar signs and visual acuity. The patients were examined by CT scan (EMI CT 1010 head scanner) and received enhancement with tothalamate sodium $70 \% \mathrm{w} / \mathrm{v}$ (Conray) unless they had a history of allergy or refused this examination. One patient refused enhancement, but she had obvious tumour on the unenhanced scan.

\section{Results}

The average age at surgery was 12 years six months (range from four years four months to 30 years 11 months) with no sex bias. Symptoms and signs prior to surgery are summarised in table 2. The average duration of symptoms was two years and four months (range from six weeks to 10 years) and the average time from the first presentation to a physician to definitive surgery was 11.4 months (range from two weeks to seven years).

\section{SURGERY AND FOLLOW-UP}

In 26 cases tumour was considered to be totally removed by the surgeon at the first operation. In the remaining 17 cases, subtotal or partial excision was performed (table 1). Six patients were left with poor vision. If the visual acuity was J6 (Jaeger reading scale) or worse on admission, the result was subsequent blindness or marked visual impairment, but if the acuity was $\mathrm{J} 4$ or better, then vision returned to 
Table 1 Detail of patients

\begin{tabular}{|c|c|c|c|c|c|c|c|c|c|c|c|c|}
\hline Patient no & $\begin{array}{l}\text { Sex } \\
\text { oper }\end{array}$ & $\begin{array}{l}\text { nd agc } \\
\text { ion } \\
Y r\end{array}$ & $\begin{array}{l}\text { at } \\
m t h s\end{array}$ & $\begin{array}{l}\text { Follow-up (to } \\
\text { nearest year) }\end{array}$ & $\begin{array}{l}\text { Site of } \\
\text { tumour }\end{array}$ & $\begin{array}{l}\text { Appearance of tumour } \\
\text { at initial operation }\end{array}$ & $\begin{array}{l}\text { Pathology } \\
\text { of tumour }\end{array}$ & Removal & $\begin{array}{l}\text { Rech } \\
\text { oper } \\
\text { Yr }\end{array}$ & $\begin{array}{l}\text { irrence } \\
\text { ated } \\
\text { mths }\end{array}$ & Present state & $C T$ scan \\
\hline 1 & $\mathbf{M}$ & 4 & 8 & 28 & LH & SC & $\mathbf{J}$ & $\mathbf{T}$ & - & & A & $\mathbf{R}$ \\
\hline 2 & $\mathbf{F}$ & 12 & 3 & 27 & RH BS & SC & $\mathbf{J}$ & $\mathrm{T}$ & - & & A & TO \\
\hline 3 & $\mathbf{F}$ & 4 & 4 & 27 & $\mathrm{RH}$ & $\mathrm{CN}$ & J & $\mathrm{T}$ & - & & A & TO \\
\hline 4 & $\mathbf{F}$ & 7 & 0 & 17 & LH & $\mathbf{s}$ & $\mathbf{J}$ & $\mathrm{T}$ & - & & $\begin{array}{l}\text { Died head } \\
\text { injury (NSR) }\end{array}$ & - \\
\hline 5 & $\mathbf{M}$ & 6 & 4 & 25 & $\mathrm{RH}$ & $\mathrm{SC}$ & $\mathbf{J}$ & $T$ & - & & A & TO \\
\hline 6 & $\mathbf{F}$ & 8 & 1 & 24 & V RH BS & $\mathrm{S}$ & $\mathbf{J}$ & $\mathrm{P}$ & - & & A & TB \\
\hline 7 & M & 12 & 6 & 23 & LH & SC & $\mathbf{J}$ & $\mathrm{T}$ & - & & A & $\mathrm{TB}$ \\
\hline 8 & $\mathbf{M}$ & 13 & 0 & 16 & RH BS & SC & D & $P$ & 14 & 0 & Died recurr. & - \\
\hline 9 & $\mathrm{~F}$ & 13 & 2 & 22 & $\mathrm{~V}$ & SC & $\mathrm{D}$ & $\mathbf{P}$ & - & & A & TO \\
\hline 10 & $F$ & 15 & 0 & 21 & $\mathrm{~V}$ & SC & $\mathrm{J}$ & $\mathrm{T}$ & - & & A & $\mathbf{R}$ \\
\hline 11 & $\mathbf{M}$ & 17 & 0 & 20 & V & SC & J & $\mathrm{T}$ & - & & $\mathbf{A}$ & $\mathbf{R}$ \\
\hline 12 & $\mathrm{~F}$ & 13 & 0 & 19 & LH & SC & J & $\mathrm{T}$ & - & & A & TO \\
\hline 13 & $\mathbf{M}$ & 9 & 11 & 19 & RH & $\mathrm{CM}$ & $\mathbf{J}$ & $\dot{T}$ & -- & & A & TO \\
\hline 14 & $\mathbf{M}$ & 15 & 1 & 17 & RH & $\mathrm{CN}$ & J & $\mathrm{T}$ & - & & A & $\mathbf{R}$ \\
\hline 15 & $\mathbf{F}$ & 6 & 3 & 17 & LH & $\mathrm{SC}$ & $\mathbf{J}$ & $\mathbf{T}$ & - & & A & TA \\
\hline 16 & $\mathbf{M}$ & 7 & 0 & 3 & LH V BS & $\mathrm{S}$ & J & $\mathbf{P}$ & 3 & 1 & Died recurr. & - \\
\hline 17 & $\mathbf{F}$ & 5 & 0 & 3 & $\mathrm{RH}$ & $\mathrm{CN}$ & J & $\mathrm{T}$ & 2 & 9 & Died recurr. & - \\
\hline 18 & $\mathbf{M}$ & 10 & 4 & 14 & RH & $\mathrm{s}$ & J & $\mathbf{P}$ & 6 & $\begin{array}{l}4 \& \\
11\end{array}$ & A & TA \\
\hline 19 & $\mathbf{M}$ & 16 & 4 & 12 & RH & SC & $\mathrm{D}$ & $\mathrm{T}$ & - & & A & TA \\
\hline 20 & $\mathbf{M}$ & 14 & $\mathbf{0}$ & 12 & RH & SC & $\mathbf{J}$ & $\mathrm{T}$ & - & & A & TB \\
\hline 21 & $\mathrm{~F}$ & 6 & 0 & 0 & $\mathrm{RH}$ & $\mathbf{s}$ & D & $\mathbf{P}$ & - & & Died recurr. & - \\
\hline 22 & M & 10 & 4 & 12 & $\mathbf{R H}$ & SC & J & $\mathrm{T}$ & - & & A & $\mathbf{R}$ \\
\hline 23 & $\mathbf{M}$ & 30 & 11 & 12 & V LH BS & SC & J & $\dot{P}$ & - & & A & $\mathrm{TC}$ \\
\hline 24 & $\mathbf{M}$ & 21 & 4 & 3 & RH BS & $\mathbf{S}$ & D & $\mathrm{P}$ & 3 & 0 & Died recurr. & - \\
\hline 25 & $\mathrm{~F}$ & 15 & 7 & 10 & LH & $\mathrm{CN}$ & J & $\mathrm{T}$ & - & & A & TB \\
\hline 26 & $F$ & 7 & 6 & 8 & V RH LH & SC & $\mathbf{J}$ & $T$ & - & & A & TO \\
\hline 27 & M & 6 & 8 & 6 & V & SC & $\mathbf{J}$ & P & - & & A & TA \\
\hline 28 & $\mathbf{F}$ & 12 & 5 & 6 & LH V & $\mathbf{S}$ & J & $\mathbf{T}$ & -- & & A & To \\
\hline 29 & $\mathbf{F}$ & 13 & 1 & 6 & V BS & SC & $\mathrm{D}$ & $\mathrm{P}$ & - & & A & TC \\
\hline 30 & $\mathbf{F}$ & 11 & 1 & 4 & RH V & $\mathrm{S}$ & J & $T$ & - & & $\mathbf{A}$ & TA \\
\hline 31 & $\mathbf{M}$ & 11 & 11 & 5 & RH V & SC & J & $\dot{P}$ & - & & $\mathbf{A}$ & TO \\
\hline 32 & $\mathrm{~F}$ & 6 & 4 & 5 & LH & SC & $\mathbf{J}$ & $\mathrm{T}$ & 3 & 2 & A & TO \\
\hline 33 & $\mathrm{~F}$ & 9 & 0 & 4 & $\mathrm{~V}$ & $\mathbf{S}$ & D & $\dot{P}$ & 0 & 10 & A & TO \\
\hline 34 & $\mathbf{M}$ & 8 & 6 & 4 & RH & $\mathrm{CN}$ & D & $T$ & 1 & 7 & SR & TC \\
\hline 35 & $\mathbf{M}$ & 5 & 0 & 3 & $\mathrm{v}$ & $\mathrm{CN}$ & $\mathbf{J}$ & $\mathbf{P}$ & - & & A & TC \\
\hline 36 & $\mathbf{F}$ & 11 & 3 & 3 & V BS & SC & J & $\mathbf{P}$ & - & & A & TC \\
\hline 37 & $\mathrm{~F}$ & 5 & 9 & 1 & $\mathbf{R H}$ & SC & D & $\mathbf{P}$ & 0 & 9 & Died recurr. & - \\
\hline 38 & $\mathbf{F}$ & 6 & 10 & 3 & RH & $\mathrm{CN}$ & $\mathbf{J}$ & $\mathbf{T}$ & - & & A & TC \\
\hline 39 & $\mathrm{~F}$ & 18 & 2 & 2 & $\mathrm{RH}$ & $\mathrm{CN}$ & $\mathbf{J}$ & $\mathrm{T}$ & - & & A & TO \\
\hline 40 & $\mathrm{~F}$ & 12 & 0 & 1 & LH & SC & $\mathbf{J}$ & $\mathbf{T}$ & - & & A & TB \\
\hline 41 & M & 12 & 0 & 1 & V BS & SC & $\mathbf{J}$ & $\mathbf{P}$ & - & & A & TC \\
\hline 42 & $\mathbf{M}$ & 14 & 10 & 1 & $\mathbf{R H}$ & SC & J & $\mathrm{T}$ & - & & $\mathbf{A}$ & TO \\
\hline 43 & $\mathbf{M}$ & 12 & 1 & 1 & V BS & SC & D & $\mathbf{P}$ & - & & A & TC \\
\hline
\end{tabular}

Column 2: $M=$ male $F=$ female; Column $4: \mathrm{LH}=$ left hemisphere $\mathbf{R H}=$ right hemisphere $\mathbf{B S}=$ brainstem; $\mathrm{V}=$ vermis; Column 5 : $\mathrm{S}=$ solid $; \mathrm{C}=$ cystic $; \mathrm{CN}=$ cystic with mural nodule $;$ Column $6: \mathrm{J}=$ juvenile $; \mathrm{D}=$ diffuse $;$ Column $7: \mathrm{T}=$ total; $\mathbf{P}=$ partial; Column 9 : $A=$ alive and well $;$ NSR $=$ no sign of recurrence (at post mortem); $\mathbf{S R}=$ symptomatic of recurrence; $\mathbf{R}=$ refused $;$ for TO, TA, TB and TC see text under CT scan.

Table 2 Symptoms and signs on presentation

\begin{tabular}{lll}
\hline & No of patients & Per cent \\
\hline Headaches & 42 & 97 \\
Vomiting & 38 & 88 \\
Ataxia & 41 & 95 \\
Papilloedema & 39 & 90 \\
Reduced vision & 6 & 16 \\
Strabismus & 14 & 33 \\
Facial palsy & 11 & 26 \\
Palatal palsy & 1 & 2 \\
\hline
\end{tabular}

normal. Visual failure in all six cases was due to optic atrophy following hydrocephalus. It appeared that once actual visual impairment accompanied papilloedema a degree of consecutive optic atrophy was inevitable despite quick surgical relief of raised ventricular pressure. Only one of these six patients had enlarged ventricles on follow-up scan. Patients whose ataxia and dysequilibrium failed to improve after initial surgery were liable to early clinical recurrence of their tumours, particularly where tumour was known to have been left. Thus nine patients had marked ataxia after operation and five of these patients died of tumour (table 1). Of the other four patients, one had a large tumour on follow-up CT scan, one a small tumour and two no obvious tumour. However, minimal residual ataxia particularly noted on heel to toe gait testing was present in all but four of the remaining 27 cases. 
There was no operative mortality at initial surgery in this series. However, out of the 11 patients who had second operations for recurrence, five died within three months of surgery. One of these patients had meningitis and this was a contributory factor along with her recurrent tumour as a cause of death (Case No 37, table 1). The other four died of massive tumour recurrence; but none of these recurrences was due to histologically "malignant" tumour. Shunts were used in patients when appropriate, after 1964.

\section{RADIOTHERAPY}

The policy of this Neurosurgical Unit has been to give radiotherapy only to those patients who were known, or thought to have, tumour recurrence. "Prophylactic" radiotherapy was not given to any patients in this series. The average follow-up in this study was 14.5 years (range 1-28 years, table 1 ).

MACROSCOPIC APPEARANCES AT TIME OF SURGERY

The preponderance of right-sided tumours is well known. ${ }^{1510}$ Nine out of 10 patients with midline tumours were over 11 years of age. The tumours were grouped according to their macroscopic appearance at surgery as solid and cystic $25(58 \%)$, single cyst with a mural nodule $9(21 \%)$ and solid 9 $(21 \%)$.

\section{NEUROPATHOLOGY}

The material on 41 cases was examined microscopically without prior knowledge of the clinical data of survival of individual cases. All the tumours were benign. They were divided into juvenile $(J)$ (33 cases) or diffuse (D) astrocytomas (10 cases) according to the classification of Russell and Rubenstein ${ }^{7213}$ (table 1). This classification was used as it was generally easily applicable, fairly reproducible and avoided terminological confusion. ${ }^{10}$ The incidence of juvenile and diffuse astrocytomas corresponds to previous series 61012 as summarised in table 3 . No malignant tumours of the kind reported in other studies ${ }^{1014}$ were encountered in this material. The juvenile tumours were characterised by stellate astrocytes, numerous microcavities of variable diameter often with scalloped amorphous pale eosinophilic luminal material and areas of more compact fibrillated fusiform cells.

The diffuse tumours had a more uniform spread of cells. In contrast with the juvenile group microcavities were scanty. The nuclei of the cells generally lacked pleomorphic features often lying in a background of compact or loose glial fibrils. Additional features were seen including calcospherules (ranging from particles to fairly large masses), foci of necrosis, occasional mitoses, Rosenthal fibres, oligo-
Table 3 Incidence of juvenile and diffuse astrocytomas in children

\begin{tabular}{llll}
\hline Series (year) & No of patients & Juvenile & Diffuse \\
\hline Crawford, 1958 & 60 & $48(80 \%)$ & $12(20 \%)$ \\
$\begin{array}{l}\text { Russell and Rubinstein, } \\
\quad 1977\end{array}$ & 91 & $77(85 \%)$ & $13(15 \%)$ \\
$\begin{array}{l}\text { Gjerris and Klinken, } \\
\quad 1978\end{array}$ & 44 & $31(70 \%)$ & $13(30 \%)$ \\
Present study & 43 & $33(76 \%)$ & $10(24 \%)$ \\
\hline
\end{tabular}

dendrogliomatous areas and patches of vascular proliferation were noted in both groups (see table 4). However, additional features proved unhelpful in further classification of these tumours as they are common to both the juvenile and the diffuse type of astrocytomas. Although some tumours were described as a nodule in a cyst, the cyst wall was included, but more by chance. Tumour in continuity with gliotic or normal cerebellum was noted in both groups of patients (table 4). No specific histological features appeared to predict reliably the course of the tumour in an individual case. Recurrence retained the original "diffuse" or "juvenile" appearance, although one patient developed an oligodendrocytic appearance at the second recurrence. There were no "malignant" recurrences.

Table 4 Comparison of additional histological features in 41 patients

\begin{tabular}{|c|c|c|c|c|}
\hline \multirow[t]{2}{*}{ Feature } & \multicolumn{2}{|c|}{ Juvenile (31) } & \multicolumn{2}{|c|}{ Diffuse (10) } \\
\hline & $\begin{array}{l}\text { No of } \\
\text { patients }\end{array}$ & Percent & $\begin{array}{l}\text { No of } \\
\text { patients }\end{array}$ & Percent \\
\hline Calcospherules & 12 & 31 & 2 & 20 \\
\hline Foci of necrosis & 2 & 6 & 1 & 10 \\
\hline Mitoses & 6 & 19 & 2 & 20 \\
\hline Rosenthal fibres & 24 & 77 & 6 & 60 \\
\hline Vascular proliferation & 17 & 54 & 3 & 30 \\
\hline Cerebellum & 23 & 74 & 6 & 60 \\
\hline
\end{tabular}

CT SCAN

The diagnosis before operation of cerebellar tumours in children by CT scan is very accurate..$^{15-18}$ Thus Kazner et al ${ }^{15}$ diagnosed 83 out of 87 cerebellar tumours at first scan and all 87 tumours after repeat scan. However, the scan of the posterior fossa after operation is more difficult to interpret. It is essential that enhancement with a suitable contrast medium is used and this is illustrated in fig 1. The scan (fig 1a) of a patient four years after initial surgery shows a normal cystic post-operative cavity, which does not enhance with contrast medium. Figure $1 \mathrm{~b}$ shows a similar cavity in a patient three years after initial surgery; enhancement (fig 1c) now reveals a suspected massive tumour. It is important to choose the cuts carefully; the scan (fig 2a) of an asymptomatic 

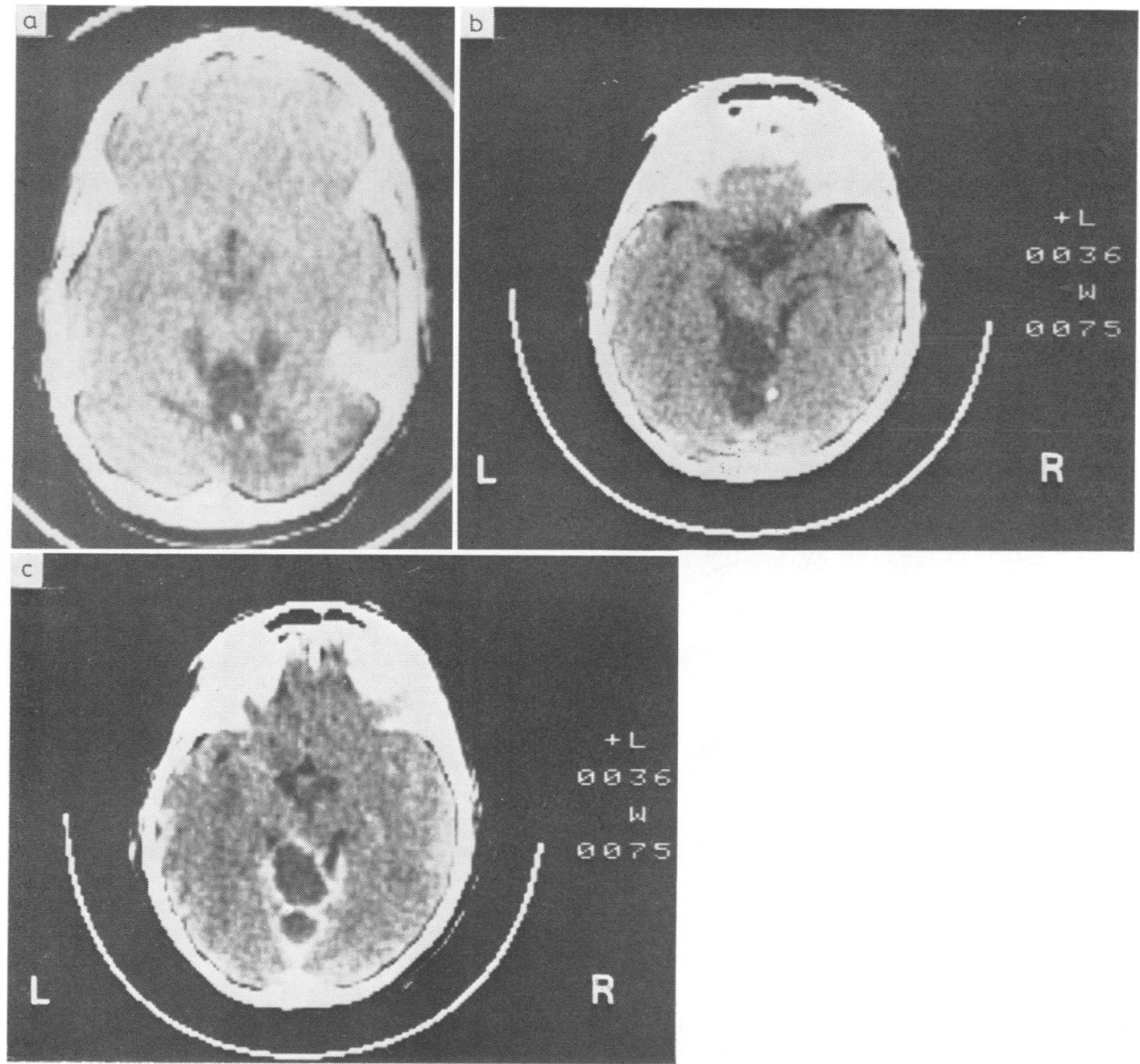

Fig 1 (a) Normal cavity four years after total removal of tumour in right hemisphere and vermis (case 13). Note small area of calcification, but no enhancement. (b) Similar appearances three years after partial excision of a tumour in the vermis involving the brain stem (case 36). (c) With enhancement a large cystic tumour is demonstrated. Both patients are asymptomatic.

patient 12 years after partial removal of tumour from the region of the left cerebellar hemisphere, vermis and fourth ventricle only shows absence of visualisation of the fourth ventricle. A slightly lower cut (fig 2 b) now reveals a suspected tumour remnant.

Scans after operation usually show evidence of surgery, usually a cavity, unless obliterated by tumour. The density of the contests of these cavities was emphasised by Zimmerman et al. ${ }^{18}$ They found that the density of cavities containing tumour after operation ranged from $6 \cdot 1$ to 10.9 EMI units as compared with cavities containing cerebrospinal fluid (CSF) which range from $3 \cdot 3$ to $4 \cdot 1$ EMI units. This observation offers a useful diagnostic aid in scan interpretation, but there are exceptions. Firstly, tumour nearly always regrows at the site of previous surgery and a small tumour lying in the side of a "normal" cystic cavity may be present, whilst the fluid is in fact still circulating CSF (fig 4c). Secondly, we believe cavities after operation may become encysted from the normal flow of CSF with resulting stagnation, giving a different density. Figure 1a shows a deep cavity after operation with no firm evidence of tumour recurrence; the cavity density is 

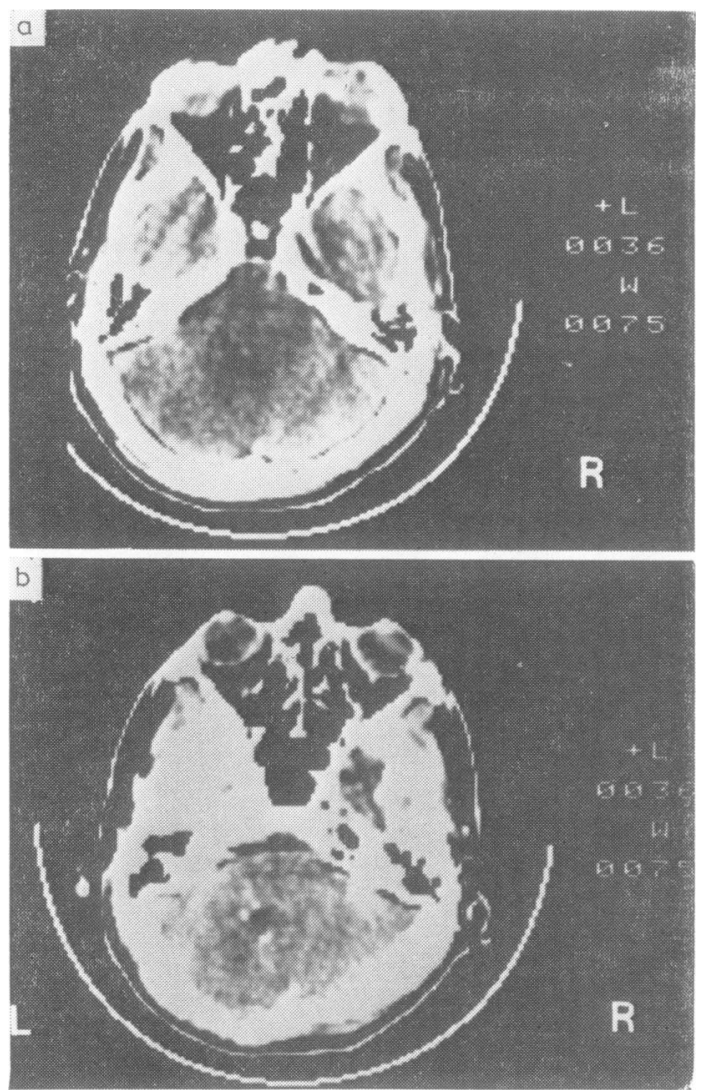

Fig 2 (a) An asymptomatic patient 12 years after partial removal of tumour from the left cerebellar hemisphere, vermis and fourth ventricle. The fourth ventricle is not visualised. (b) Lower cut reveals tumour remnant.
12 EMI units, whereas CSF measures 3 EMI units. Cyst densities were measured in our patients and although the majority of suspected cystic tumour recurrences had a higher density than CSF there was a wide range of measurements making this unreliable. Sometimes scans are particularly difficult to interpret.

Table 5 Current state of 31 surviving patients on scan appearances

\begin{tabular}{llc}
\hline Tumour group on scan & \multicolumn{2}{l}{ Excision at initial surgery } \\
\cline { 2 - 3 } & Partial (12) & Total (19) \\
\hline TO & 3 & 10 \\
TA & 2 & 3 \\
TB & 1 & 4 \\
TC & 6 & 2
\end{tabular}

TO-no tumour, TA-small non-enhancing abnormal area at original site of tumour, TB-small enhancing area suspicious of tumour and unlike scar, TC-suspected tumour recurrence with definite enhancing area.

Figure 3 illustrates this in a patient treated at another hospital ten years previously with surgery and radiotherapy. Recently he presented with progressive cerebellar signs and the scan (fig 3a) shows a cystic cavity with a small anterior enhancing area (fig $3 \mathrm{~b}$ ) and possible radiation changes in the cerebellar hemispheres. At surgery only gliotic tissue was found after an extensive exploration. A small enhancing area as in this case may cause diagnostic difficulty as it may represent "scar" or an abnormal vascular pattern.

With these aspects in mind the assessment of tumour presence on CT scan appearance has led to the following classification.

1 No tumour (TO) (fig 4a)
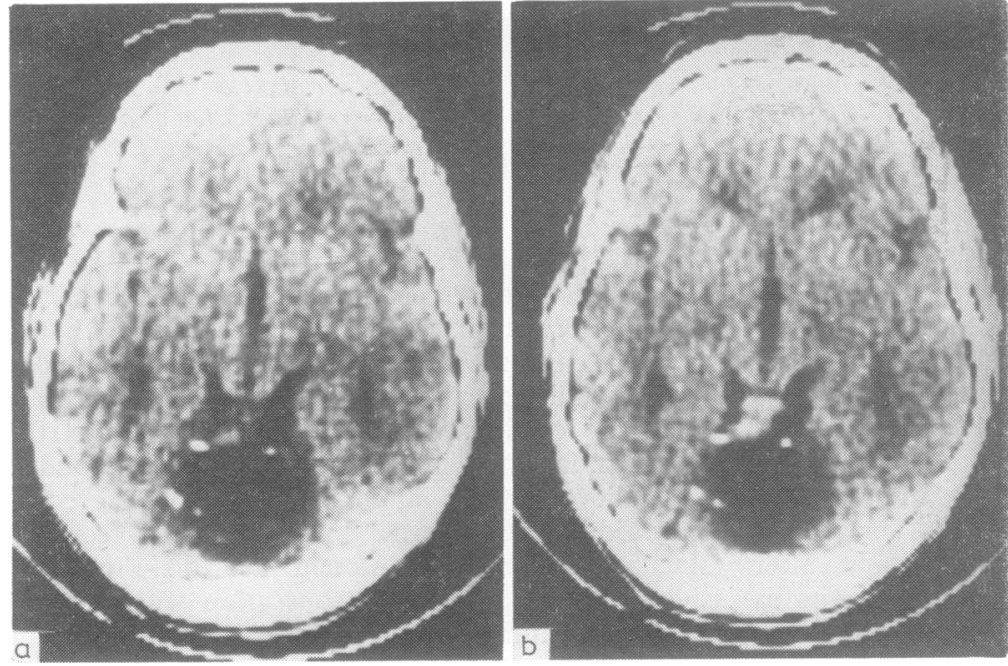

Fig 3 Thirty-year-old patient with six months progressive ataxia ten years after surgery and radiography. Cystic cavity ( fig $3 a$ ) with small anterior enhancing "scar" or blood vessel ( fig 3b). Possible cerebellar radiation necrosis. No tumour found at surgery. 

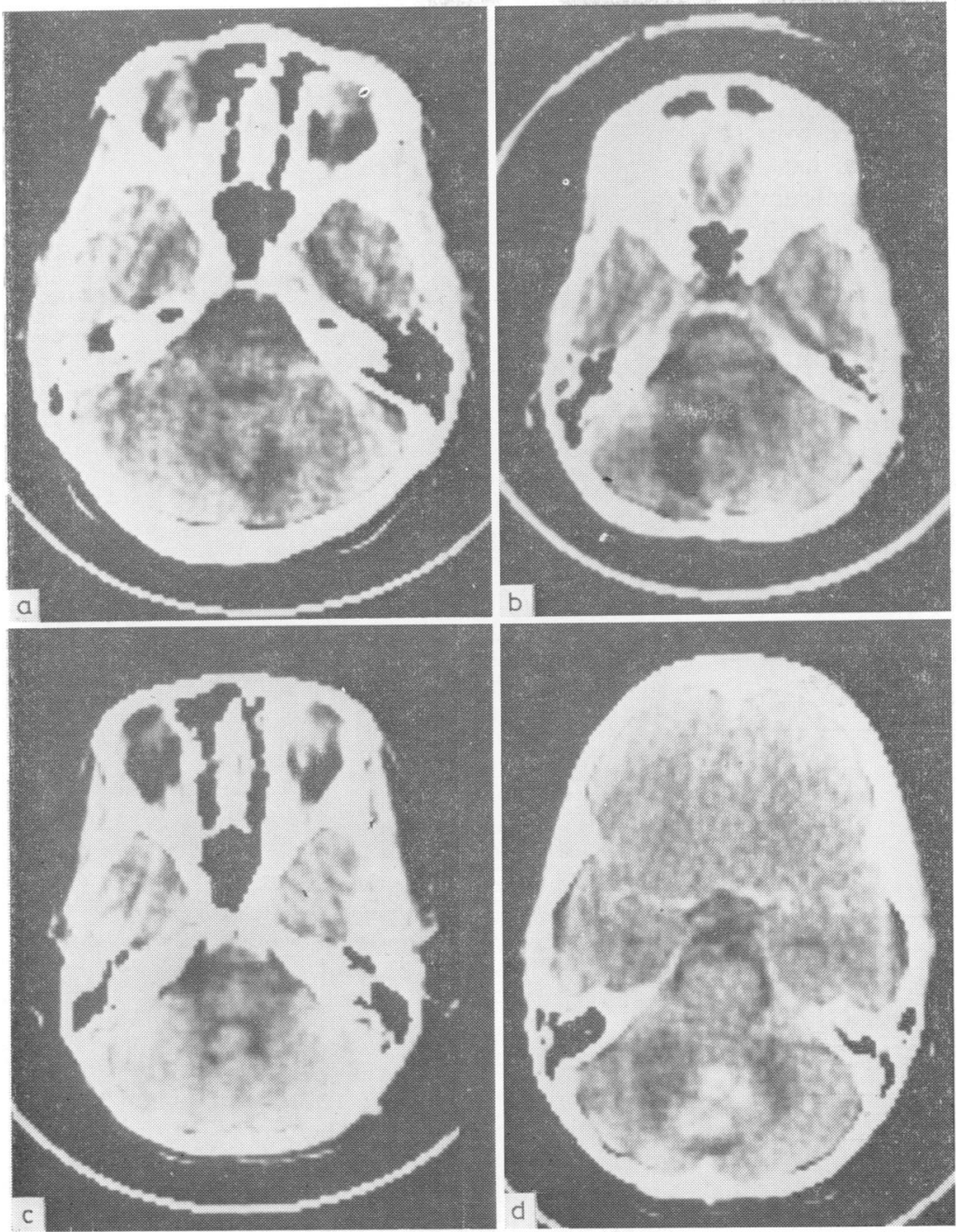

Fig 4 (a) Normal post-operative cavity 27 years after surgery for tumour in right hemisphere (case 3). (b) Small enhancing area suggestive of tumour near midline in cavity 16 months after total removal of left hemisphere tumour (case 40). (c) Small enhancing tumour in fourth ventricle 14 months after partial removal of tumour involving left cerebellar hemisphere, inferior cerebellar peduncle and fourth ventricle (case 4I). (d) Large suspected tumour three years after sub-total removal of vermis tumour (case 35). All patients in this group are asymptomatic.
2 Small non-enhancing abnormal area at o:iginal site of tumour (TA) (fig 1a)

3 Small enhancing area suspicious of tumour and unlike scar (TB) (fig 4b)

4 Probable tumour with large enhancing area (TC) (figs 1c, 4c, 4d)

Tables 5 and 6 show the outcome related to the extent of initial surgery. Total macroscopic tumour removal is associated with a better prognosis, and of 25 patients, only one has died of tumour; four, however, have strong evidence of suspected tumour on CT scan and one patient has symptomatic recurrence. Where the surgeon suspects that he has left tumour behind the prognosis is much worse: CT scanning has not been available for long enough to add weight to the surgeon's operative findings, but of these 18
Table 6 Outcome related to extent of initial surgery

\begin{tabular}{llc}
\hline & Partial & Total \\
\hline $\begin{array}{l}\text { Died from tumour } \\
\text { early-5 vears }\end{array}$ & 4 & 1 \\
Died from tumour & & \\
$\quad$ late & 1 & 0 \\
CT scan TO, TA & 5 & 13 \\
CT scan TB, TC & 8 & 5 \\
Well refused scan & 0 & 5 \\
Died, no sign & 0 & 1 \\
recurrence & 0 & \\
\hline
\end{tabular}

TO, TA, TB, TC-see table 5.

patients, four have died within 5 years of tumour "regrowth" and one of late "recurrence". Eight patients are asymptomatic but have strong evidence 
of tumour still present, and surprisingly, five patients have no tumour present on CT scan. The prognosis is thus clearly related to the extent of the initial surgery. We have performed serial scans in five patients suspected of large recurrence over the last 2 years. Only one of these patients has been shown to have a consistently enlarging tumour. The other four suspected tumours do not have a linear growth rate and, indeed, one of them appears to have shrunk. The remaining three suspected tumours appear to be static.

Tables 7 and 8 show the relationship between histology and follow-up and current CT scan appearance. Early and proven recurrence was more likely to be associated with the "diffuse" histological pattern (see also table 1); however, late proven "recurrence" and suspected tumour on CT scan was not associated with any particular histological features.

Table 7 Relationship of histology to follow-up (43 cases)

\begin{tabular}{|c|c|c|c|c|}
\hline & "Juvenile" & $\begin{array}{l}2 n d \\
\text { operation }\end{array}$ & "Diffuse" & $\begin{array}{l}\text { 2nd } \\
\text { operation }\end{array}$ \\
\hline Died-recurrence & 0 & 2 & 1 & 3 \\
\hline Died-no recurrence & 1 & $\mathbf{0}$ & 0 & 0 \\
\hline CT scan group TO & 10 & 1 & 1 & 1 \\
\hline TA & 3 & 1 & 0 & 1 \\
\hline TB & 5 & $\mathbf{0}$ & 0 & 0 \\
\hline TC & 5 & $\mathbf{0}$ & 2 & 1 \\
\hline Refused scan & 5 & 0 & 0 & 0 \\
\hline
\end{tabular}

"2nd operation"- operation for clinical recurrence. TO, TA, TB, TC-see table 5.

Table 8 Follow-up and CT scan appearance (31 cases)

\begin{tabular}{lllll}
\hline & \multicolumn{3}{l}{$C T$ scan appearance } & \\
\cline { 2 - 5 } & $T O$ & $T A$ & $T B$ & $T C$ \\
\hline 0- 5 years & 3 & 1 & 1 & 6 \\
5-10 years & 4 & 1 & 0 & 1 \\
10-15 years & 0 & 2 & 2 & 1 \\
15-20 years & 2 & 1 & 0 & 0 \\
20-25 years & 1 & 0 & 2 & 0 \\
25-28 years & 3 & 0 & 0 & 0 \\
Total & 13 & 5 & 5 & 8 \\
\hline
\end{tabular}

TO, TA, TB, TC-see under table 5.

The scans also revealed another group of 15 asymptomatic patients with enlarged ventricles. Six patients had markedly increased ventricular size (fig 5) and nine patients a moderate increase in ventricular size.

\section{Discussion}

Cerebellar astrocytoma is one of the commonest CNS tumours of childhood, and there has been consistent improvement in their surgical treatment since Cushing. ${ }^{1-4} 1011131920$ There was no operative

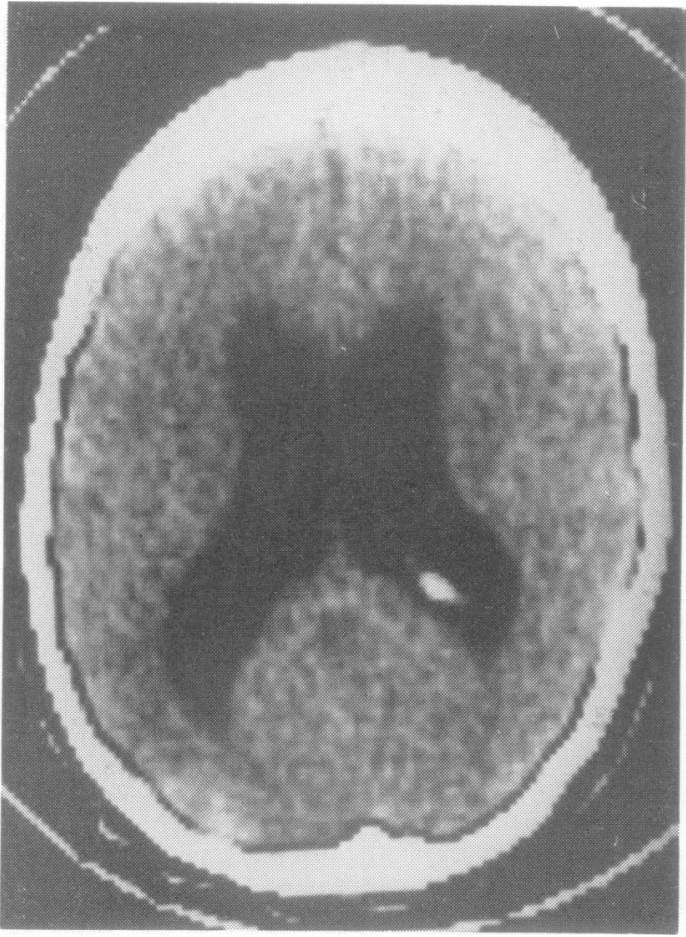

Fig 5 Increased ventricular size 19 years after uneventful surgery. No tumour recurrence and the patient is asymptomatic with no signs of hydrocephalus (case 12).

mortality in this series at initial surgery and neurological morbidity was associated with tumour regrowth in most cases. There are still, however, a large number of patients being referred with failing vision $(16 \%)$. In this study the extent of initial surgery and the histology have been shown to be the only helpful factors in predicting tumour "recurrence", though this is not always the case (tables 1,5 , 7). The age, sex, site of tumour and surprisingly the macroscopic appearance at operation have been shown to be of no use in predicting the long term prognosis.

CT scan is the most accurate radiological detector of intracranial tumour ${ }^{15-18}$ and more importantly, appears to detect tumour before clinical manifestation of recurrence; in this series 12 suspected recurrences were found in asymptomatic patients. It would appear unlikely that all these patients will develop clinical recurrence; however, it has been shown from previous reviews ${ }^{1-1320}$ that the longer patients are followed, the more will need further surgery, sometimes after many years. Some may question the interpretation of suspected tumour on a 
single CT scan in an asymptomatic patient. In patients whose tumour was partially removed it would not be surprising to find tumour remnant on CT scan and the factors which may cause this to grow, perhaps many years later, are not known. Only 1 of our 12 positive CT scans has been proven at surgery. However there is also a definite group of "recurrences" in patients whose tumours were thought to have been totally removed (table 7), though the majority of these operations were before the days of CT scanning. Again, the CT scan shows that nearly half the patients with tumour left at operation appear to have had spontaneous resolution.

In our clinical experience, recurrences are large before symptoms return; there are several possible reasons for this: the patients may have large skulls and posterior fossae due to the slow evolution of hydrocephalus prior to suture fusion, and there is also a surgical decompression and sometimes a shunt. Nearly half the patients scanned had enlarged ventricles unrelated to the presence or absence of tumour or shunt (table 1). It will be interesting to see if any develop symptoms of raised pressure or "normal pressure" hydrocephalus.

There appear to be three different patterns of recurrence; firstly, that occurring within 4 years of initial surgery, in the younger patient, which is more likely to be associated with the "diffuse" group of tumours. Secondly, the later recurrence, unrelated to histological group or extent of initial surgery, and apparently unpredictable; thirdly, a rare form of late recurrence due to the malignant transformation of a previous indolent tumour has been reported. ${ }^{14}$ This may be related to the earlier use of radiotherapy and was not present in our series. Once symptoms of recurrence appear, the tumour is large and the operative mortality and morbidity is high. Five out of our eleven patients who had surgery for recurrent tumour died within three months.

The role of radiotherapy for the treatment of this group of patients is unclear and debatable. Some neurosurgeons refer patients routinely for radiotherapy after initial surgery; this is because they feel that even if there has been a "total" removal of tumour, there may be microscopic remnants. However, no controlled trials have been carried out and the numbers of patients given this form of treatment tend to be too small for any one centre to produce reliable results. Given the generally benign histological appearance of most of these tumours and the possible malignant transformation with radiotherapy, we feel this form of treatment should not be used "prophylactically", although the CT scan may yield more information in the future to alter this approach.
The CT scan poses a new dilemma in patient management as the neurosurgeon is usually reluctant to operate on asymptomatic cases. He may be unwilling to follow-up asymptomatic patients for a long period of time. The known indolent course in the majority of cases suggest a conservative approach and repeated follow-up scans could distress the parents and children. Against this is the known higher morbidity and mortality on subsequent surgery for large recurrence, which may present after many years. Many of these patients are young and early treatment could well give them an almost normal lifespan with minimal disability. Based on this study, it is our view that a carefully planned CT scan long-term follow-up is essential in the management of all these patients. Prognosis might improve in the group as a whole if recurrences are detected and treated early.

We thank Dr RD Hoare, neuroradiologist, for reviewing the $\mathrm{CT}$ scans. We also thank $\mathrm{Mr} \mathrm{PH}$ Schurr, Mr JJ Maccabe, Mr CE Polkey (Neurosurgical Unit), Dr I Janota (Department of Neuropathology) for their help and advice, and Mr RS Maurice-Williams of the Regional Neurosurgical Unit of the Brook General Hospital for permission to give details of the patient illustrated in figure 3 .

\section{References}

${ }^{1}$ Cushing H. Experiences with cerebellar astrocytomas: a critical review of 76 cases. Surg Gynaec Obstet $1931 ; 52: 129-204$.

${ }^{2}$ Bodian M, Lawson D. Intracranial neoplastic diseases of childhood. Br J Surg 1953;40:383-5.

${ }^{3}$ Elvidge AR. Long term survival in astrocytomas series. J Neurosurg 1958;28:399-404.

${ }^{4}$ Gol A, McKissock W. The cerebellar astrocytomas: a report on 98 verified cases. J Neurosurg 1959;16: 287-96.

${ }^{5}$ Mabon RF, Svien HJ, Adson AW, Kernohan JW. Astrocytomas of the cerebellum. Arch Neurol Psychiatry 1950;64:74-88.

${ }^{6}$ Matson DD. Cerebellar astrocytomas in childhood. Paediatrics 1956;18:150-8.

' Russell DS, Rubinstein LJ. Pathology of Tumours of the Nervous System, ed 4. London: Edward Arnold, 1977:183-90.

${ }^{8}$ Till K. Paediatric Neurosurgery for Paediatricians and Neurosurgeons. Oxford: Blackwell Scientific, 1975: 1-57.

${ }^{9}$ Winston K, Gilles FH, Leviton A, Fulchiero A. Cerebellar gliomas in children. J Nat Canc Inst 1977; $58: 833-8$.

${ }^{10}$ Geissenger JD, Bucy PC. Astrocytomas of the cerebellum in children: long term study. Arch Neurol $1971 ; 24: 125-35$.

$11 \mathrm{Gol} \mathrm{A}$. Cerebellar astrocytomas in children. Am J Dis Child 1963;106:21-4. 
${ }^{12}$ Crawford JV, Rubinstein LJ, Russell DS. Follow-up of cerebellar astrocytomas in relation to their pathology. J Neurol Neurosurg Psychiatry 1958;21: 64.

${ }^{13}$ Gjerris F, Klinken L. Long term prognosis in children with benign cerebellar astrocytomas. $J$ Neurosurg 1978;49:179-84.

${ }^{14}$ Kleinman GM, Schoene WC, Walse TM, Richardson EP. Malignant transformation of benign cerebellar astrocytoma. J Neurosurg 1978;49:111-8.

${ }^{15}$ Kazner E, Meese W, Kretzschmar K. The role of computed tomography in the diagnosis of brain tumours in infants and children. Neuroradiology 1978;16:10-12.

${ }^{16}$ Naidich TP, Lin JP, Leeds NE, Pudlowski RM, Naidich JB. Primary tumours and other masses of the cerebellum and fourth ventricle: differential diagnosis by computed tomography. Neuroradiology 1977;14:153-74.

${ }^{17}$ Probst FP, Liliequist B. Assessment of posterior fossa tumours in infants and children by means of computed tomography. Neuroradiology 1979;18:9-18.

${ }^{18}$ Zimmerman RA, Bilaniuk LT, Bruno L, Rosenstock J. Computerised tomography of cerebellar astrocytoma. Am J Roentgenol 1978;130:929-33.

${ }^{19}$ Fulchiero A, Winston K, Leviton A, Gilles FH. Secular trends of cerebellar gliomas in children. J Nat Canc Inst 1977;58:839-43.

${ }^{20}$ Gjerris F. Clinical aspects and long term prognosis of intratentorial intracranial tumours in infancy and childhood. Acta Neurol Scandinav 1978;57:31-52. 